\title{
Systemic design for sustainability
}

\author{
Markus Schwaninger ${ }^{1}$ (I)
}

Received: 14 July 2017 / Accepted: 4 February 2018

(C) Springer Japan KK, part of Springer Nature 2018

\begin{abstract}
How can we restore the ecological balance of our planet? The present article is aimed at contributing a structural framework for such a restoration. In the quest for ecological recovery, cybernetic-systemic approaches are in demand. They specialize in coping with complexity and offer new, transdisciplinary and non-reductionist ways of system design for renewing sustainability. This contribution uses a proven model from organizational cybernetics—-the viable system model—as a frame for sustainable development. The model specifies how the viability of any human or social system can be achieved by means of clearly defined organizational structures. In accord with the logic of recursive organization inherent in the model, a proposal for a structural design aimed at enabling ecological recovery is formulated. That design includes all organizational levels of recursion, from individual to world. The implications of such a novel approach are far-reaching, and the impact powerful.
\end{abstract}

Keywords Sustainability $\cdot$ Ecological balance $\cdot$ Organizational cybernetics $\cdot$ Systems design $\cdot$ Organization ·

Transdisciplinarity $\cdot$ Recursive structure $\cdot$ Cyber-systemic thinking

\section{The quest for ecological balance}

In the 30 years since the United Nations' World Commission on Environment and Development defined sustainable development, the improvements have been piecemeal. What we see may become a deluge of monstrosities-a gigantic squandering of resources, pollution of air, soil and water, depletion of biodiversity, altogether: a disruption of the web of life. In this situation, the burning question arises: "Who will restore the ecological balance of the planet, and how can it be done?"

The claims about where the urgently needed renewal should come from are controversial. Many assert that the issue rests at the individual level, where minds, attitudes and behaviors are decisive for a sustainable course of events. Others maintain that the locus of control must be at world level, where effective regulation can and should take place. The proposition of this paper is not only different but also more differentiated. We suggest that sustainability can be

Handled by Marialuisa Saviano, University of Salerno, Italy.

Markus Schwaninger

markus.schwaninger@unisg.ch

1 University of St. Gallen, St. Gallen, Switzerland attained only if ecological balance is achieved ${ }^{1}$ at each of the various levels, from individual to family to municipality to region to province, department, or state to nation state to continent to world. Issues of sustainability become manifest at any of these levels, and they must be "solved" there: with the proviso that solving a problem may entail the need to reach beyond the level where that problem appears, if the cause rises on another plane. Hence, the "how" of ecological restoration is at the discretion of each recursive level.

\section{A cybernetic proposal: the viable system model (VSM)}

Our proposal is based on the cybernetic concept of viability. If one wants to organize for sustainability, one needs to organize for viability.

\footnotetext{
1 The two concepts are closely related: ecological balance has been defined as «a term used to describe the equilibrium between living organisms such as human being, plants, and animals as well as their environment.» (Thompson 2017). A recent definition of sustainability has emphasized the dynamics of ecological systems: “... a dynamic equilibrium in the processes of interaction between a population and the carrying capacity of its environment such, that the population develops to express its full potential without producing irreversible adverse effects on the carrying capacity of the environment upon which it depends." (Ben-Eli 2012).
} 
There are different options of models for the management aimed at the goal of viability (Miller 1978; Aubin 1997; Beer 1981, 1984, 1985; Adam 2000). For our study, we have chosen the viable system model (VSM), which, of the options examined, is the strongest model in its theoretical claim and falsifiability, as well as its diagnostic potency and aptitude for design. The claim is that this model specifies the sufficient preconditions for any social system to be viable (Beer 1984). This prerogative reaches much further than the mere reference to "necessary requirements", for the VSM has not been falsified, or in other words, has not been proven to be wrong. Serious attempts to falsify the model have not been successful (Frost 2005; Crisan Tran 2006; Schwaninger and Scheef 2016). Therefore, following the falsification principle (Popper 2002), it can be assumed that the model stands up to its claim. Consequently, we shall revert to the VSM as a guideline.

In the VSM, a set of "control mechanisms" is specified, which Beer describes as the necessary and sufficient preconditions for the viability of any human or social system.

The theory of the VSM claims that a social body is viable if and only if it has a dovetailed structure of regulatory units whose functions and inter-relationships are precisely specified in the theory. Here is a resume of the generic structure of the model (e.g., Beer 1985; Schwaninger 2009; Pérez Ríos 2012):

To start with the basic units: these might be divisions if we look at a firm, departments, provinces, or states if we look at a nation, nations if we look at a continent, and continents if we look at the world. These basic units absorb the respective complexity of the environment they are confronted with.

A set of regulatory functions or management subsystems make up the complete model:

System 1-“Implementation": the regulatory capacity of the largely autonomous, adaptive basic units.

System 2-"Coordination": coordination function providing the dampening of oscillations and enhancing self-regulation.

System 3-“Integration": typically the executive corporate management, which provides overall direction, striving for a global optimum (transcending the local optima of basic units), and allocation of resources.

System 3*-“Auditing": audit and monitoring system, which complements the vertical channel (3-1) and the horizontal, anti-oscillatory coordination system.

System 4-"Intelligence": stands for long-term orientation and dealing with the overall environment. Company development/strategic management.

System 5-"Ethos": strikes a balance between the shortand long-term orientation, as well as internal and external perspective. Ethos of the system-values and norms, normative management.
So far, we have laid out the necessary and sufficient preconditions for viability. In the outlined structure, Systems 1, 2 and 3 make up the operative system, while Systems 3, 4 and 5 are the metasystem. System 3 here provides the linking pin which is a part of both the operative system and the metasystem.

An additional important device are the algedonic signals,- - alerting devices which decide if signals of imminent danger (or exceptional opportunity) must be sent directly to the top management.

The viability, cohesion and self-organization of a social body depend upon the functions outlined above being recursively present at all levels of its organization. Hence, viable systems are structured recursively. The sequence $R_{x, \ldots, z}$ denotes levels of recursion ranging from $x$ to $z$. Units of lower levels are embedded in units of higher levels:

$R_{z} \subset R_{y} \subset R_{x} \subset R_{w}$

Viable systems are fractals, i.e., they are self-similar in that their basic structure repeats itself at different levels of recursion

$R_{z}: R_{y}: R_{x}: R_{w}$

A recursive structure comprises autonomous units within autonomous units. Moreover, a viable social system, e.g., a company, is made up of viable units and is itself embedded in more comprehensive viable units (Fig. 1; after Beer 1979: 315). Each unit, inasmuch as it is producing the organization's task rather than servicing or supporting this production, replicates - in structural terms - the totality in which it is embedded. So we meet the same structure over and over along the levels of the organization.

The VSM is treated in more detail in Beer's original work and Pérez Ríos (2012) among others. Several authors have provided methodological guidance for the application of the VSM (e.g., Espejo and Harnden 1989; Espejo et al. 1996; Hoverstadt 2008; Schwaninger 2009; Espejo and Reyes 2011; Pérez Ríos 2012). In addition, many case studies about uses of the VSM in diverse contexts have been published; an overview can be found in Schwaninger (2009: 107f.), and Schwaninger and Scheef (2016).

Autonomy is basic to the VSM. From Greek "autos" (for self-) and "nomos" (for law) this term refers to the primary unit as a whole being "a law unto itself", as Beer defined it (Beer 1981). The autonomy in question is, therefore, both a system's freedom and the responsibility to regulate itself. This is the pivot of an organization's adaptation and learning.

Whenever the challenges confronted exceed the capability of such a primary unit, it becomes necessary to join forces. In many cases, this can be achieved by a horizontal cooperation. However, it can also indicate the necessity of jointly constituting a new unit at a higher level of recursion. For 


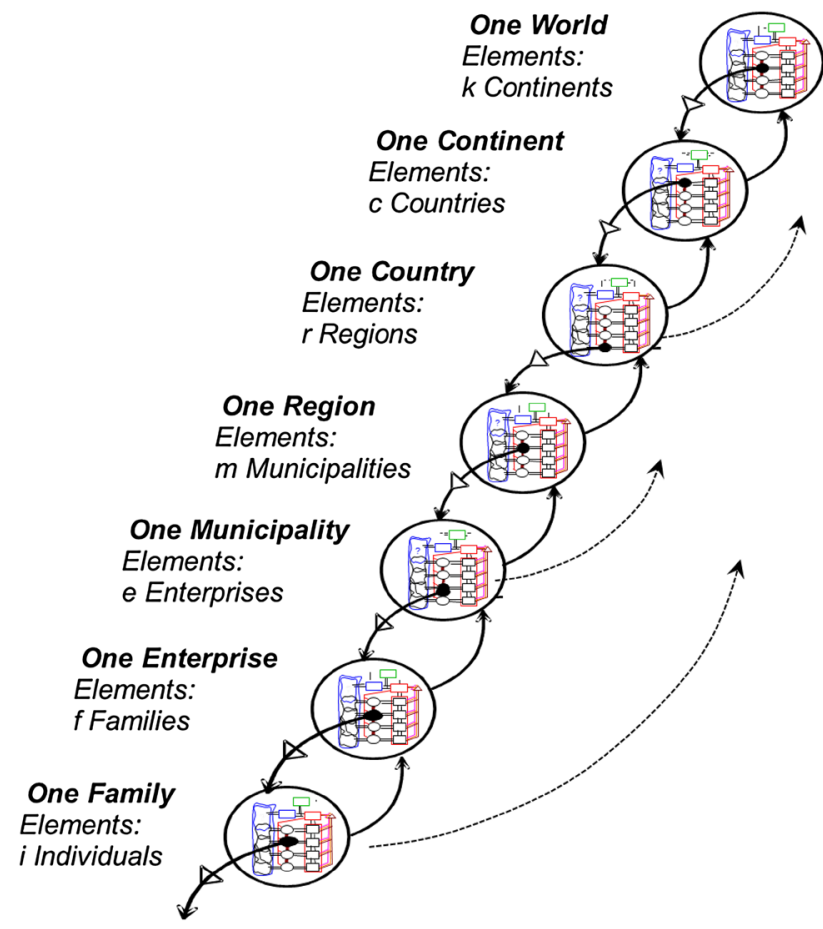

Fig. 1 Structural preconditions for sustainable development-a multirecursion view

example, municipalities form states and states form nation states.

The formation of a new organizational unit is not necessarily linked to a merger of all aspects of the activities of the Systems. For example, two or more units can join forces to deal with the ecological challenge in a more prolific way than if they go on their own (see: Schwaninger 2015).

\section{A structural framework for sustainability}

We can now apply the VSM in support of ecological sustainability. The coming sections are based on earlier work by the author (Schwaninger 2006, 2015). The difference is that here the theoretical part is extended, while the cases in support of the argument, which are partially new, are more concise.

Instead of starting at the global level, we shall begin with the individual agent. One often hears that sustainability starts in the head of the individual that acts (or not) according to ecological principles. However, agents exist at different levels, if you look at the world from a system-theoretic perspective. For example, we can identify a whole company as one agent. Let us take Interface, the leading producer of carpet tiles, a company that excels in its ecological commitments: Closed loop products, zero environmental footprint, and a restorative approach, to name just a few. The late Ray
Anderson, whom we interviewed a few years ago, was the initiator of this orientation ${ }^{2}$.

But today, when Interface announces that it wants to be "a corporation that cherishes nature and restores the environment", and is guided by a "Mission Zero commitment" ${ }^{3}$, it speaks with one voice, as a single agent.

In addition, the aggregated results of the strategies to make this vision come true will be measured and reported in organs of the corporation as a whole. On lower levels of recursion, different divisions, teams or staff members will develop their own views, values and strategies, by following the logic, "What is my contribution to our mission?"

As we know, strong and viable organizations thrive on that mutual alignment of values, strategies and actions, from bottom to top and from top to bottom.

Hence, we conceive of agents as human or social units, acting as wholes, at different recursive levels of a human or social system. In the context of the quest for sustainability, we can now outline an idealized structure of the multiple agents concerned (Fig. 1).

In this scheme, the structure reaches from the level of the individual to the level of the whole world. At first, one might think that the multiplicity of agents forming the system at all of these levels is prohibitive to an endeavour of mapping all of them at once.

Why is this diagram so simple? Because it uses the recursion principle: Wholes at multiple strata absorb complexity along the fronts at which that complexity emerges. The reach of this recursive structure is practically infinite. This structure lets one visualize how each level handles its regulatory issues in its own right. To maintain viability, each agent has to deal with that task of absorbing the specific complexity by which he or she is affected, in accordance with Ashby's Law of Requisite Variety, which says, "Only variety can absorb variety". ${ }^{4}$

Ashby's advice is the principle for the design which we are presenting. Requisite variety is the nucleus of viability.

Issues of ecological (and social) sustainability arise everywhere, but they vary according to the planes. It makes no sense to try to solve the pothole problem at the global level, for that is the task of every mayor in each city or village. On the other hand, prohibiting a toxic substance is often a national or international issue. But a company can act even faster by interdicting that substance in its own plant or creating an incentive for not using it (for example, a fine per kilo,

\footnotetext{
2 The path of Ray Anderson to ecologically committed entrepreneurship is documented in Anderson (1998).

3 Corporate homepage: http://www.interfaceglobal.com/Company/ Mission-Vision.aspx. Accessed 7 March 2017.

4 Ashby's original wording was: „Only variety can destroy variety“. (Ashby 1956.) Beer inserted the more insightful verb "absorb" (Beer 1979).
} 
as practised in a few pioneering companies). In principle, the approaches to sustainability management need to be customized on different planes; a single approach would be insufficient. However, the organizational framework is one that provides closure among multiple strata (Fig. 1).

Most affairs can be regulated at the bottom, so that higher levels should regulate only what cannot be taken care of at the lower ones. This corresponds to the principle of subsidiarity. ${ }^{5}$

The lines drawn top-down indicate the unfolding of viable systems along different recursive strata. The solid lines drawn bottom-up symbolize the principle of subsidiarity as well as the participation, mainly in regulatory activities, of higher-level bodies. The dotted lines, bottom-up, symbolize the possibility of such participation in recursions beyond the next immediate one.

New or parallel recursions might also emerge from networks of communication, - the interactions in the Internet and multimodal communication. One example is the possible formation of a self-contained unit at a higher level of recursion, by individuals who aggregate, via online connections. Top-down, the respective media enable microtargeting, i.e., a method of reaching individuals, over the net, with individualized messages. Analogically, these media can, bottom-up, enable the cohesion of great numbers of individuals around a vital common purpose. Several initiatives that focus on ecological sustainability have been formed in that way (Castells 2013). Whether they are durable depends on their institutional basis; social initiatives devoid of such a basis tend to be ephemeral (Dubois and Dutton 2014). Ultimately, their viability hinges on the organizational properties outlined here.

The principle of recursion multiplies the capacities of complexity absorption. It is applicable ad infinitum, and therein lies its tremendous power. Processes of self-organization arise on each plane, as well as along the vertical lines of the recursive architecture. These processes are distributed and to some degree spontaneous, bringing about the structural and behavioral pattern of a system within current bounds of system parameters, e.g., goals, values, and business model. The main triggers here are fluctuations and feedback.

At this point one can ask: does emergence-the emanation of new system properties, namely qualitative changes of identity,-also happen in such an organizational context? It

\footnotetext{
${ }^{5}$ Subsidiarity is an organizing principle according to which a central authority should have a subsidiary function, performing only those tasks which cannot be performed effectively at a more immediate or local level (after the Oxford English Dictionary). In other words, "a matter ought to be handled by the lowest, smallest and least centralized authority capable of addressing that matter effectively" (http:// en.wikipedia.org/wiki/Subsidiarity. Accessed 7 March 2017).
}

can indeed. Emergence can arise from environmental stimuli (major fluctuations ${ }^{6}$ ), or from synergy between subsystems, as well as from self-reference in the metasystem of the organization.

In several cases, companies have reinvented themselves as pioneers of sustainability, with deep implications for their identities, strategies and structures. The Interface and Continental corporations, to which we will refer in the next section, are only two cases in point.

\section{Cases of self-development: the organizational level}

At this point, we would like to share with readers some of the experience accumulated in our research team. We have studied and applied these theoretical foundations over decades and in the most diverse contexts.

The following abridged case studies document three examples of self-development ${ }^{7}$ : first, self-enhancement, second, self-improvement and third, self-transformation. The first example provides a general overview of a standard way of organizing for sustainability, based on the case of a medium-sized industrial company. Examples 2 and 3 relate to two large companies that transformed themselves from organizations without any particular interest in ecology, to enterprises deeply committed to ecological and social sustainability. In both of these transformations, self-referencein the sense of self-reflexion-played a key role, as a way of higher-order learning ${ }^{8}$.

\footnotetext{
${ }^{6}$ In this context, Prigogine's theory of dissipative systems, with its concept of "order through fluctuation", is crucial: Nonlinear systems under conditions far from equilibrium can pass over into new situations, in which fluctuations play a central role. These fluctuations can force the system to leave a given macroscopic state (Prigogine 1976).

7 Development is used here as an overarching concept in the sense of Ackoff (1981): it denotes the growing ability and desire of a system to satisfy its own and others' needs. Depending on the definition it can reach out beyond viability (Schwaninger 2009). In relation with the cases presented, we are subsuming three activities-which need not be collectively exhaustive-under "development": enhancement, improvement and transformation. Here we use the self-referential variant of the concepts: the prefix "self" invokes the autonomic nature of the respective functions.

8 The distinctions made here are on the one hand between first-order learning,- - the learning through error correction,- - and second-order learning, via changes of goals and other crucial parameters, which can involve a complete redesign of a system. In addition, meta-learning, or what Bateson (1973) called "deutero-learning" (pp. 140ff.), denotes the aspect of learning to learn (better).
} 


\section{Case 1-Self-enhancement: organization for achieving and maintaining sustainability}

Self-enhancement is normally defined as maintenance of self-esteem, a motive that becomes prominent in situations of threat. We consider self-enhancement mainly as an ongoing process and an observed effect (Sedikides and Gregg 2008). We also assume that this concept can be transferred from individual psychology, where it originates, to the social sciences, and therewith to organizations. Here, the concept is slightly extended: We conceive of self-enhancement as the maintenance of the integrity of self, vis-à-vis threatening forces. In the following, the case of an enterprise is analyzed, which organized itself to reinforce its sustainability and viability.

As an exemplar, we take Chemix $^{9}$, a mid-sized industrial company in Switzerland from the chemical industry. Much of the following structure is a result of design, but in an incremental way, along an evolutionary path.

Let us now walk through the sustainability-related tasks as they are distributed across the functions of the VSM:

\section{System 1}

This is about regulation and optimization of ecological management, in the short term, of the basic units. We are referring to the general management provided by the business unit heads and factory managers, who ensure environmentand security-related direction and control.

\section{System 2}

Coordinates the ecological efforts across the basic units, and provides educational programs, as well as planning and control of ecology-related programmes. The main agents here are a small service unit for sustainability and quality assurance, and a "sustainability circle" with members of different sections. In this System-2function, the circle is the prime diffusion medium for ecological consciousness. The instruments used include an ecological accounting system, and environment- and quality-related standards of behavior and knowledge bases.

\section{System 3}

Here, we have the overall responsibility for sustainable operations of the company. In charge is one of the three executives of the management board. The sustainability unit (see System 2) reports to this executive.

\footnotetext{
${ }^{9}$ Name anonymized.
}

\section{System 3*}

Is about the auditing and monitoring for ecological efficiency, through direct access to the basic units. Ecological audits and special environment-related investigations into the operations are important here, besides informal interactions of higher managers with workers.

\section{System 4}

The long-term orientation concerning sustainability has several contributors, namely research and development and the sustainability circle (in its System-4-function), all coordinated by the sustainability staff. The latter does the systematic work on corporate development and strategy, such as investigation and modeling. The top executives are part of the strategic management process, and all of these efforts are tied together in the hands of the CEO.

\section{System 5}

Determines the identity of the organization and its functions in the environment, by incorporating the supreme values and norms, in short, the ecological ethos of the system as a whole (Normative management). The CEO is the protagonist and main catalyst of the corporate values seconded by the board. Pertinent instruments are the corporate charter (with values and business mission), and a sustainability vision statement. The corporate charter was elaborated with the participation of employees from all sectors.

This setup gets close to the ideal type of a VSM-based structure. No wonder, then, that Chemix is arguably one of the best managed in the country, in ecological terms. By the way, empirical studies indicate that high environmental performance goes hand in hand with superior overall performance, e.g., Meffert and Kirchgeorg (1992:190).

This was a case that embraced one recursion level-the company as a whole. Let us now take an example with three levels of recursion, in the second case.

\section{Case 2-Self-improvement: evolution of strategy and structure}

This is a case in which an organization improves itself in an effort of design and implementation. We are referring to a larger company, - the Continental Corporation, with whom we have been collaborating for many years. Continental is an organization dedicated to mobility and transport, best known for its tires and steering systems.

Since the entrance of a new CEO several years ago, the quest for sustainability has been enforced at Continental. The management there is convinced that the effort for sustainability is more than environmental protection: it must 
Fig. 2 Circular concept of the value chain (value cycle)

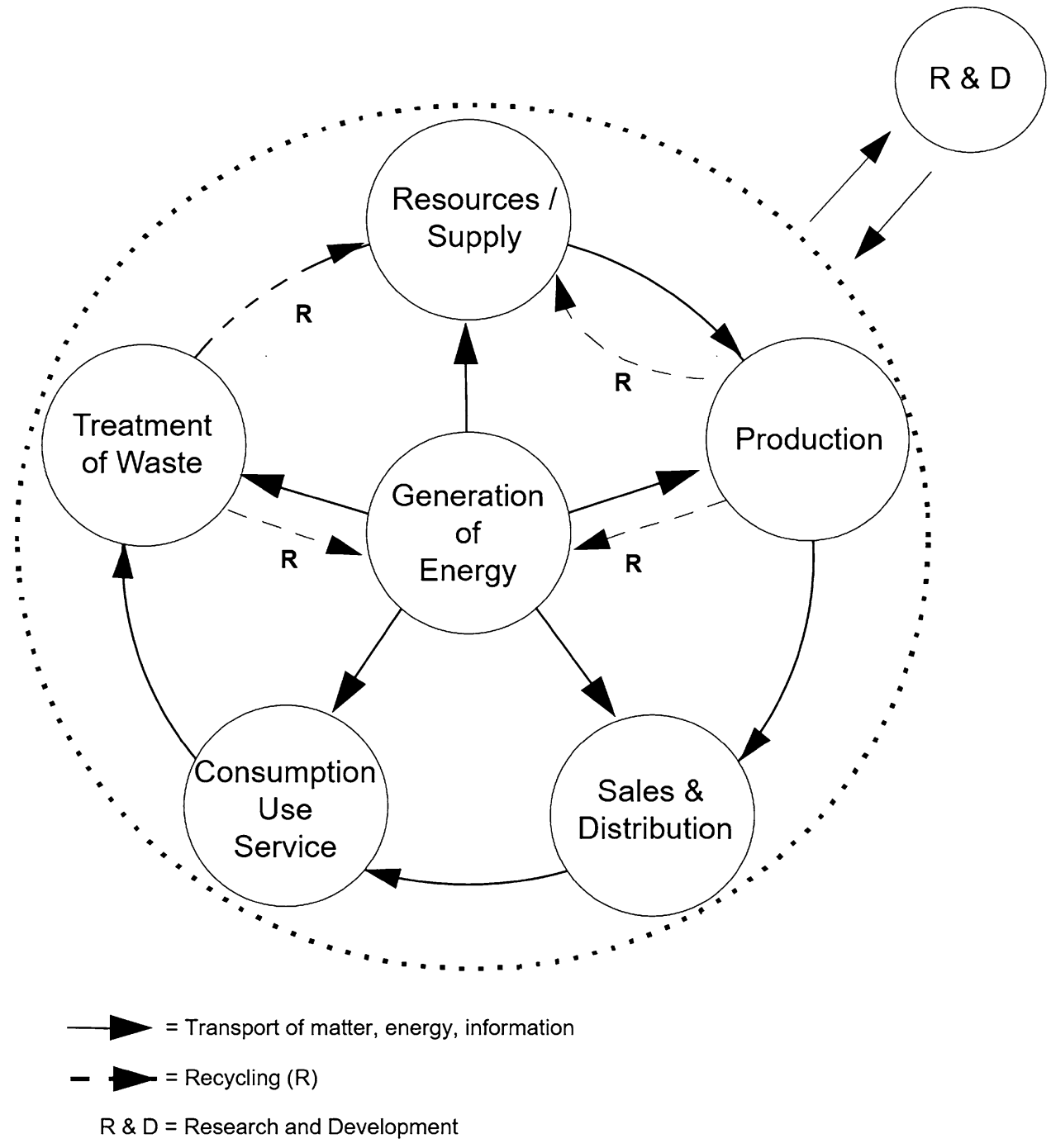

reach beyond end-of-pipe measures and be organized in a circular fashion (Fig. 2). And it must be deeply ingrained in all domains: starting from research and development and going to the supply chain, production, and the entire value chain. Product responsibility at Continental embraces the complete life cycle of a product. The company strives for minimal consumption of resources and the minimization of immissions on humans and the environment.

Therefore, Continental's approach is convincing: First, the pursuit of ecological and social sustainability companywide is considered a task of each member of the organization. This norm is contained in the leadership principles and practices.

Second, responsibility for the greening of the firm is anchored throughout the line (Fig. 3). At the level of top management to begin with: The ultimate responsibility for the sustainability of the company, in all respects, is with the chairman of the executive board ("CEO") together with the executive board as a whole ("Vorstand"). The CEO carries the line responsibility for quality and environment (System 3 ). At his side is a strong service unit called "Corporate Quality and Environment", which has very much a 2-3* function, in terms of the VSM. There is a second-related line function for corporate social responsibility, with the executive board member for human resources (part of System 3). There are also other mechanisms of coordination, such as rules and procedures, not only for quality and environment, but also for security, health, etc.

The long-term issues of sustainability (System 4) are regularly handled by the Corporate Social Responsibility Council. The supreme tenets and principles (System 5) are well documented in corporate values and mission statements. This system is carried down to the divisional recursion. Here again, we find the same structure in all five divisions (Tires, three Automotive Divisions and Continental Technologies). And the same logic continues further down.

The arrangement of tasks, as outlined, shows what Ashby's Law already taught us: ecological and social 
Fig. 3 Ecological management at Continental

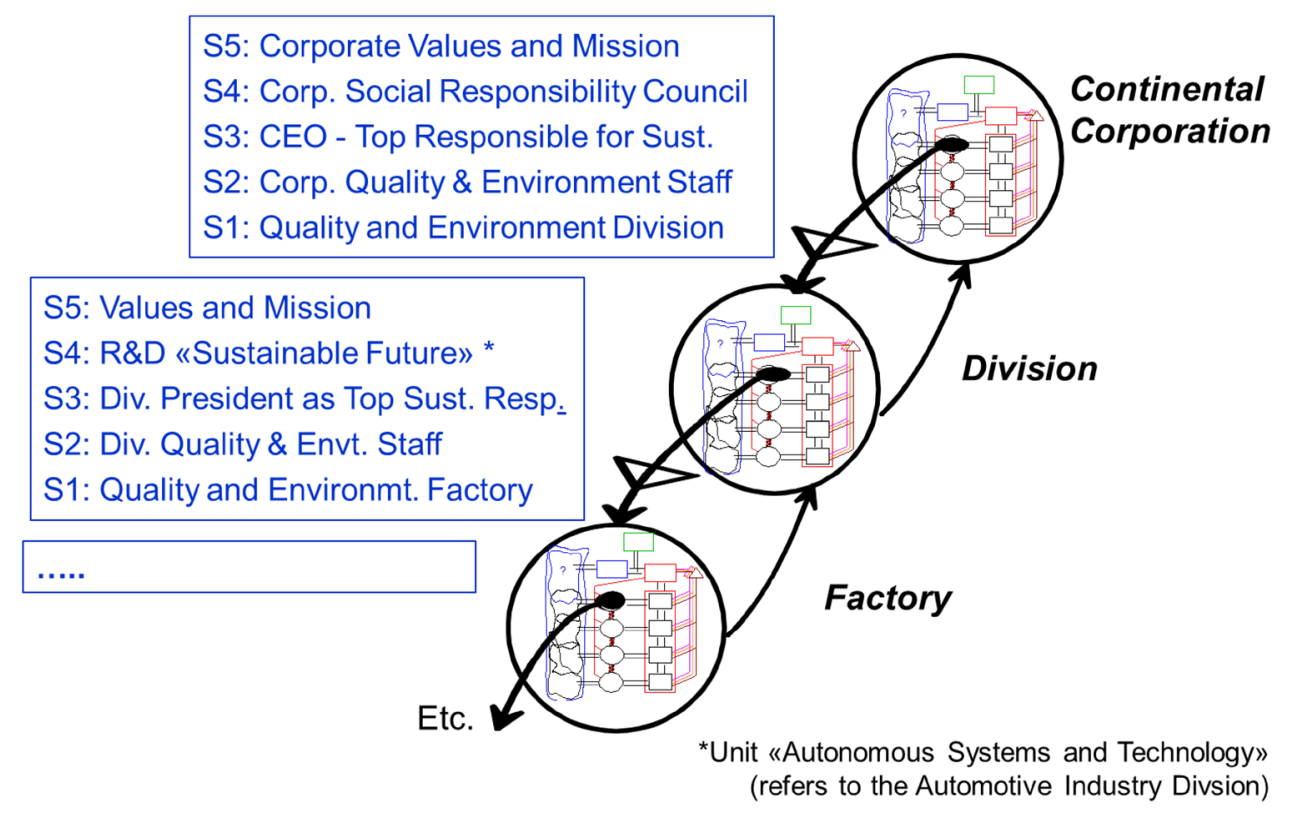

External stimuli and self-referential processes can trigger the emergence of new properties in a system. The following case draws on evidence from an organization that supplies a prominent instance of such a process. Here, we chiefly highlight the influence of the metasystem on a company's trajectory.

Interface is the world's largest manufacturer of carpet tiles. Back in the 1980s, Ray Anderson, the founder and CEO of the company, experienced an "epiphany" as the crucial stimulus which suddenly and fundamentally changed his outlook, and with it the company as such: an ecologically virtuous pattern of corporate behavior surfaced (Anderson 1998). Here, the stimulus for fundamental transformation originated with the person who was at the core of the System-5-function. Hence, the case was clearly top-down. Even after Anderson's death, in the years following 2010, the ecological orientation continues vigorously. The company presents itself as follows: "Interface ${ }^{\circledR}$ is the worldwide leader in design, production and sales of environmentally responsible modular carpet for the commercial, institutional, and residential markets". ${ }^{10}$ During its journey, Interface has reached impressive milestones, e.g., a 90\% reduction of its carbon footprint in Europe, where - as of January 2017-the plant is operating with $100 \%$ renewable energy, using virtually zero water in manufacturing processes, and attaining zero waste to landfill.

This example vividly illustrates the importance of System 5 for processes of organizational transformation. The founder of the company was the embodiment of normative management, "preaching" the ecological values. The further

$\overline{10}$ http://www.interfaceglobal.com/ (Accessed 22 March 2017). 
management systems-strategic (System 4) and operative (Systems 1-3) - took on those values and adapted their structures to the main orientation. That top-down sequence ultimately led to the impressive ecological performance.

\section{Examples: higher levels of recursion}

So far, we have examined three examples located at the recursion "organizations" (level $e$ in Fig. 1). Similar cases from other recursive planes should be analyzed as well, the aim being to visualize the framework presented here, in operation at all levels, from individual to world.

Moving up the ladder of recursions, we can now begin to assess and design the structures for sustainability at the levels of community, region, and nation. At these levels, some notable successes have already been achieved.

A first endeavor to document in detail a case at the regional plane has been accomplished (Schwaninger 2012). The Gastein Valley, one of the most beautiful alpine valleys, was facing a substantial threat to its sustainability and viability. This menace stemmed from a technical intervention planned by the Austrian State, as a function of its treaties with the European Union. The threat was an imminent construction of a high-volume and high-speed railway system that would have endangered the attractiveness of the valley. As tourism is the main source of economic prosperity in the valley, this project would have been a shock to its viability. In response to the threat, an enabling structure, coupled with a new culture of cohesiveness and "organizational intelligence" in the valley, emerged. It warranted viability at the (regional) level of a whole valley. That organization showed all the properties of a viable system, as documented in Schwaninger (2015).

The new organization enabled a regional movement, triggered by local citizens and amplified by a mediation forum. The result of the process was a decision for a revised project which softened the intervention: it would minimize the environmental impact (more environment-friendly, less noisy, more sustainable), demanding a substantially higher investment. The new concept was incorporated into the overall transport policy of the Austrian Ministry of Transportation, Innovation and Infrastructure, therewith obtaining quasilegal status. This result may be attributed largely to the enabling structure of viability and the culture that went with it.

Turning now to the national level, we have at least two great analytical works: One of them, providing a foundation, is a design proposal by Stafford Beer (1989) for nations in general. The other is a careful diagnosis of the Swiss political system, by Maarten Willemsen (1992), a former doctoral student of the author. His work analyzed certain implications for ecology. However, a proposal for both a diagnosis and design for sustainability at the national level remains to be accomplished. What is needed in many countries is a transition to a more effective management framework, by which fragmentation and ineffective regulation are overcome.

If we move on to the last recursions, continental and global, we discern great ecological problems but low-grade effectiveness in dealing with them. That is, at the level of the world, although many institutions try to regulate something, they achieve mixed results at best. The VSM would be a powerful means for bringing about worldwide ecological recovery.

The vision of global online communities of individuals solving problems that transcend the competency of single nations has been propagated, now, for several decades. In this respect, the idea of a global online community as an embodiment of "the values" of humanity is often discussed (e.g., Harari 2017). The values of ecological and social sustainability are on the rise (Kelly-Lainé 1997; Caniglia et al. 2013; Institut für Ökologische Wirtschaftsforschung 2014). Only the future can show, however, whether or not a resilient community of values will emerge, and how far-ranging it will be.

Networked social movements are global and local at the same time (Castells 2015), and they also embrace the intermediate strata in between. It remains to be seen, to what extent large-scale social initiatives can bring about viable units, in particular at higher levels of recursion. Sustainability will not happen if it is enforced merely from the top or pursued exclusively at the level of individuals. If we take a view of the overall recursive design, it becomes apparent that a multilevel approach is needed. The issues must be tackled at each recursive plane. None of these is unimportant or "less important".

Regulations must be focused on the needs of the specific planes to which they apply. Any fragmentation of the efforts made at regulation is an obstacle to ecological balance. We often hear that the environmental crisis results from a deficient consciousness among individual citizens. I agree. But the crisis is, in equal measure, the product of a structural deficit in the current institutional makeup.

\section{Implications and outlook}

We have made a proposal for enabling sustainability at all levels, from individual to world, by means of a systemic design.

Cybernetics offers a theory of recursive organization as a conceptual basis for such systemic design. In this vein, we are pleading for multilevel problem-solving and distributed intelligence, enabled by recursive structures. The agents at different planes of organization and recursion confront environmental complexity along the lines where it manifests itself, and they respond in self-organizing fashion. In this 
way, the capacity of an organization for dealing with complexity is multiplied. The structural principle for achieving overall sustainability is in the stratified self-organization at these different planes that cooperate for bringing about ecological balance.

In practical terms, any one of these planes needs its specific organization for an "ecological management" enabling sustainable development and renewal. Specific kinds of issues and challenges arise at each one of these levels, and that is where they must be mastered. ${ }^{11}$ In this way, complexity is absorbed wherever it manifests itself. Processes of self-organization and emergence, triggered largely by selfreference, can emanate at each level and across the strata of the system. These organizational properties should be among the foremost considerations of policy-makers when designing a framework for global sustainability.

Overcoming the current ecological imbalance calls for two things:

- First, better structural and institutional frameworks for enabling agents at each level to make their contribution.

- Second, measures to enhance the ecological consciousness of citizens and their capacity for becoming environment-friendly (Last not least, good frameworks as such should contribute to that environmental consciousness). Ultimately, the success of the ecology movement will not hinge on better structures and institutions only, but on people's knowledge, and on their love and compassion for nature.

The viable system model we have introduced makes use of Ashby's law of requisite variety: at each recursive level of the organization, the agents absorb complexity as it unfolds. This principle is as powerful as it is simple. Applying the logic represented in the viable system model to the management for sustainability could reverse the fatal course which our society has set and steer away from destruction of the environment toward ecological recovery. The present paper aims to be a contribution to such a desirable course of events.

The potential of cybernetics and systems to help humanity cope with its complex challenges and respond to global issues is huge. Until now, this potential has been actualized only to a small degree. Yet it could be definitely leveraged in the contest, or perhaps one should say warfare, for a sustainable world.

\footnotetext{
$\overline{11}$ One must add that problems often cannot be solved in the place where they appear. For the most part, complex issues must be tackled somewhere else. If the cause rests on another plane, the process of solving the problem must transcend the boundaries of the involved strata.
}

Acknowledgements The author is grateful to multiple executives from companies for their patience in responding to my questions. He wishes to thank in particular Dr. Felix Gress, Senior Vice President Communications and Public Affairs, the Continental Corporation, for providing insights into the structures and history of his organization. Many thanks to three anonymous reviewers who provided valuable comments. A token of special gratitude goes to Prof. Marialuisa Saviano and Dr. John Peck for their editorial support.

\section{References}

Ackoff RL (1981) Creating the corporate future: plan or be planned for. Wiley, New York

Adam M (2000) Lebensfähigkeit sozialer Systeme: Stafford Beer's Viable System Model im Vergleich. PhD thesis, No. 2442. University of St. Gallen, St. Gallen, Switzerland

Anderson RC (1998) Mid-course correction. Toward a sustainable enterprise: the Interface model. Chelsea Green Publishing, White River Junction

Ashby WR (1956) An introduction to Cybernetics. Chapman \& Hall, London

Aubin JP (1997) Viability Theory. Springer, Berlin

Bateson G (1973) Steps to an ecology of mind. Paladin Books, London

Beer S (1979) The heart of enterprise. Wiley, Chichester

Beer S (1981) The brain of the firm. Wiley, Chichester

Beer S (1984) The viable system model: its provenance, development, methodology and pathology. J Oper Res Soc 35(1):7-25

Beer S (1985) Diagnosing the system for organizations. Wiley, Chichester

Beer S (1989) National government: disseminated regulation in real time or "How to run a country". In: Espejo R, Harnden RJ (eds) The viable system model-interpretations and applications of Stafford Beer's VSM. Wiley, New York, pp 333-360

Ben-Eli MU (2012) The cybernetics of sustainability: definition and underlying principles. In: Murray J, Cawthorne G, Dey C, Andrew C (eds) Enough for all forever: a handbook for learning about sustainability. Common Ground Publishing, University of Illinois, Champaign, pp 255-268

Caniglia BS, Burns TJ, Gurney RM, Bond EL (2013) Rise of environmental consciousness. University Readers, San Diego, CA

Castells M (2013) Communication power. Oxford University Press, Oxford

Castells M (2015) Networks of outrage and hope: social movements in the Internet age. Polity, Cambridge

Crisan Tran CI (2006) Beers viable system model und die Lebensfähigkeit von Jungunternehmen-Eine empirische Untersuchung. PhD thesis, No. 3201. University of St. Gallen, St. Gallen, Switzerland

Dubois E, Dutton WH (2014) Empowering citizens of the internet age: the role of the fifth estate. In: Graham M, Dutton WH (eds) Society and the internet. How networks of communication are changing our lives. Oxford University Press, Oxford, pp 238-253

Espejo R, Harnden RL (eds) (1989) The viable system model, interpretations and applications of Stafford Beer's VSM. Wiley, Chichester

Espejo R, Reyes A (2011) Organizational systems: managing complexity with the viable system model. Springer, Berlin

Espejo R, Schuhmann W, Schwaninger M, Bilello U (1996) Organizational transformation and learning. A cybernetic approach to management. Wiley, Chichester

Frost B (2005) Lebensfähigkeit von Communities of Practice im organisationalen Kontext. PhD thesis, No. 3120. University of St. Gallen, St. Gallen, Switzerland

Harari YN (2017) "Sharen" ist nicht teilen. Neue Zürcher Zeitung am Sonntag 7:4-7 
Hoverstadt P (2008) The fractal organization. Creating sustainable organizations with the viable system model. Wiley, Chichester

Institut für Ökologische Wirtschaftsforschung (2014) Umweltbewusstsein und Umweltverhalten in Deutschland 2014. Vertiefungsstudie: Trends und Tendenzen im Umweltbewusstsein. In. Umwelt Bundesamt, Berlin

Kelly-Lain K (1997) Environmental education and sustainable development: trends in member countries. In: OECD (ed) Sustainable development. OECD policy approaches for the 21 st century. Organisation for economic co-operation and development, Paris, pp 174-181

Meffert H, Kirchgeorg M (1992) Marktorientiertes Umweltmanagement: Grundlagen und Fallstudien. Poeschel, Stuttgart

Miller JG (1978) Living systems. McGraw-Hill, New York

Pérez Ríos J (2012) Design and diagnosis for sustainable organizations: the viable system method. Springer, Berlin

Popper KR (2002) Logik der Forschung. 10th edn reprint. Mohr, Tübingen (originally published 1959)

Prigogine I (1976) Order through fluctuation: Self-organization and social system. In: Jantsch E, Waddington $\mathrm{CH}$ (eds) Evolution and consciousness: human systems in transition. Addison-Wesley, London, pp 93-133
Schwaninger M (2006) The quest for ecological sustainability: a multilevel issue. In: Trappl R (ed) Cybernetics and systems, vol 1. Austrian Society for Cybernetic Studies, Vienna, pp 149-154

Schwaninger M (2009) Intelligent organizations: Powerful models for systemic management, 2nd edn. Springer, Berlin

Schwaninger M (2012) Making change happen: recollections of a systems professional. Kybernetes 41(3):348-367

Schwaninger M (2015) Organizing for sustainability: a cybernetic concept for sustainable renewal. Kybernetes 44(6/7):935-954

Schwaninger M, Scheef C (2016) A test of the viable system model: theoretical claim vs. empirical evidence. Cybern Syst Int J 47(7):544-569

Sedikides C, Gregg AP (2008) Food for thought. Perspect Psychol Sci 3(2):102-116

Thompson D (2017) Ecological balance and its importance. http:// scvswap.com/2015/05/09/ecological-balance-and-its-importance I. Accessed 16 Nov 2017

Willemsen MH (1992) Ist die Schweiz ein lebensfähiges System? Kybernetische Diagnose des schweizerischen politischen Systems. Rüegger, Chur/Zürich 